\title{
LA CONFIGURACIÓN DE LAS ÉLITES POLÍTICAS URBANAS GALLEGAS EN EL PRIMER FRANQUISMO (1936-1951)
}

\author{
Configuration of the Galician Urban Political Elites in Franco's Dictatorship First \\ Years (1936-1951)
}

\author{
Adrián Presas Sobrado \\ Universidade de Vigo \\ apresas@uvigo.es \\ Orcid: 0000-0003-2809-2528
}

Cómo citar este artículo/Citation:

Adrián Presas Sobrado, "La configuración de las élites políticas urbanas gallegas en el primer franquismo (19361951)", Hispania Nova, 19 (2021): 229 a 254.

DOI: https://doi.org/10.20318/hn.2021.5881
Copyright: (C) HISPANIA NOVA es una revista debidamente registrada, con ISSN 1138-7319 y Depósito Legal M 9472-1998. Los textos publicados están -si no se indica lo contrario- bajo una licencia Reconocimiento-Sin obras derivadas 3.0 España de Creative Commons. Puede copiarlos, distribuirlos y comunicarlos públicamente siempre que cite su autor y la revista y la institución que los publica y no haga con ellos obras derivadas. La licencia completa se puede consultar en: http://creativecommons.org/licenses/by-nd/3.0/es/deed.es

Resumen: Este trabajo muestra que la configuración de la élite política urbana de la dictadura franquista en siete ciudades españolas parte del uso de hombres sin un pasado político. Gracias al estudio de la continuidad y la discontinuidad de esas élites locales, en la larga duración, la idea historiográfica sobre el mantenimiento de un sistema político continuador del caciquismo restauracionista, o de simple recuperación de la cultura política de la derecha española tradicional, en vista de los resultados obtenidos, puede ser discutida. El objetivo del trabajo es abrir un campo de debate sobre posiciones teóricas bien asentadas en la academia española.

Palabras clave: franquismo, historiografía española, élites, cultura política, caciquismo.

\begin{abstract}
This paper shows that the configuration of the urban political elites in seven Spanish cities in Franco's dictatorship was produced because of the use of non-experienced in politics men. The study of the continuity and discontinuity of these local elites in the long term, demonstrates that the historiographical idea about the maintenance of a political system which continued with the political culture of classical patronage along the Borbonic Restoration, or just recovering of the Spanish right political culture, can be discussed. The objective of this paper is opening a discussion about historiographical theories which are well established in the Spanish academia.
\end{abstract}

Keywords: Francoism, Spanish Historiography, Elites, Political Culture, Patronage. 


\section{INTRODUCCIÓN}

La configuración del proyecto político, administrativo, económico, social y cultural de la dictadura franquista ha sido cualificada por la historiografía española de diferentes maneras. Implantación, instauración, institucionalización y construcción son los cuatro conceptos que se utilizan para hacer referencia al nacimiento y desarrollo de la dictadura franquista en los planos citados. Los cuatro conceptos, sin embargo, no remiten a las mismas realidades conceptuales.

Mientras que cuando se habla de implantar, instaurar o institucionalizar se está referenciando un elemento venido de fuera, externo, ajeno, impuesto al territorio en que se sitúa; el verbo construir, nos remite a una realidad dinámica, cambiante, sometida a los condicionantes de cada territorio. Las élites políticas de la dictadura, como en todo el proceso de elaboración de los cuatro planos, deben entenderse como una construcción continuada en el tiempo y apoyada en las circunstancias de cada región.

Cuando la historiografía española se ha enfrentado al estudio de la construcción de la dictadura franquista en el ámbito local — sea este urbano o rural—, ha acabado por concluir que esta fue una continuación de la tradición política iniciada por las élites de la Restauración borbónica y de la dictadura de Primo de Rivera. Las élites, por lo tanto, aun adaptándose a un escenario de fascistización y reacción conservadora, no habrían sufrido una ruptura con la cultura política del pasado. Además, el uso de los cuatro conceptos ha sido aprovechado por la historiografía para incidir en la reflexión sobre la naturaleza política de la dictadura franquista.

La reflexión estaba agotada ya en los años 90 del siglo pasado ${ }^{1}$. Eso obliga a un estudio de las élites políticas locales de la dictadura franquista para conocer el sustento social, económico y cultural que sirvió de base a la construcción de ese régimen político. Con este estudio se pretende aportar una posible respuesta a preguntas como: ¿cuál fue el grado de continuidad y discontinuidad de los hombres que participaron en la política local con anterioridad al golpe de Estado de julio de 1936?; si se produjo una continuidad en el uso de hombres de la élite política anterior al golpe de Estado, ¿cuál

\footnotetext{
${ }^{1}$ Así lo dejaron patente, en sus respectivos trabajos, Julio Aróstegui, "La historiografía sobre la España de Franco: Promesas y debilidades", Historia contemporánea, 7, (1992): 77-100 y Javier Tusell, "La dictadura de Franco a los cien años de su muerte", Ayer, 10, (1993): 13-28.
} 
fue el grado de continuidad de esos hombres a lo largo de los primeros años de la dictadura?, y finalmente, ¿utilizó la dictadura a hombres nuevos, sin pasado político, para ocupar los puestos de responsabilidad política en los ayuntamientos estudiados? Y, de ser así, ¿en qué grado?

\section{LA SELECCIÓN DE LAS ÉLITES POLÍTICAS LOCALES EN LA HISTORIOGRAFÍA ESPAÑOLA}

Los primeros estudios en los años 80 sobre las instituciones locales en la dictadura franquista -que analizaron los discursos, la economía, el cese y nombramiento de comisiones gestoras-, se han convertido en el modelo de todos los análisis siguientes. Se acabó consolidando un esquema de estudio que se repite desde aquellos días hasta hoy².

La historiografía también profundizó en las definiciones sobre los conceptos de élite, clase y personal político. Con anterioridad a los primeros textos sobre el ámbito local aparecieron estudios que centraron su análisis de la estructura del Estado dictatorial «desde arriba». La definición de «élite» hace referencia al grupo de aquellos que participaron en política, aportando maleabilidad a las investigaciones. Es decir, élite sería el conjunto de individuos que realizaban las actividades que garantizaban la supervivencia, permanencia y pervivencia de un determinado modelo político, social, económico y cultural ${ }^{3}$.

\footnotetext{
${ }^{2}$ El punto de arranque de los estudios sobre el poder local lo marcó María Encarna Nicolás Marín, Instituciones murcianas en el franquismo (1939-1962). Contribución al conocimiento de la ideología dominante. (Murcia: Editora Regional de Murcia, 1982) con su estudio sobre la región de Murcia. Después de ella, fueron dos mujeres las que dieron los primeros pasos en el estudio de la dictadura franquista a nivel local. El estudio de la provincia de Soria fue realizado por Ana Rosa Frías Rubio, Instituciones sorianas en el franquismo. (Soria: UNED, 1988); y el de la provincia de Guipúzcoa por Cándida Calvo Vicente, Poder y consenso en Guipúzcoa durante el franquismo (1936-1951). (Salamanca: Universidad de Salamanca, 1994). También Borja de Riquer, "El «Nuevo Estado» i l'Ajuntament de Barcelona. La classe política del primer franquisme”, L'Avenç, 126, (1989): 16-22, en el caso de los ayuntamientos catalanes, hizo una pequeña aproximación que posteriormente seguirían otros. Estos estudios conservan su valor como prototipos de análisis para los historiadores que las siguieron, a pesar de que en la actualidad se han visto superados desde el punto de vista analítico; hecho normal, debido al progresivo acceso a nuevas fuentes documentales y bibliográficas.

${ }^{3}$ Es decir, que el concepto de «élite» sería «funcionalista». En base a esa misión de función, de elemento articulador y regulador, la lectura que hizo sobre el concepto Carles Viver i Pi-Sunyer, El personal político de Franco (1936-1975). (Barcelona: Vicens-Vives, 1978) éste agruparía a todos aquellos que
} 
Con el concepto de «élite» — al que se le añade el calificativo de «política»—, nace su opuesto teórico: «clase política»; de tal manera que la «clase» hace referencia a un conjunto cuyos elementos se vinculan por el hecho de participar en política. «Élite» quedaría, por lo tanto, reducida a calificar a una minoría social que, aunque efectivamente participante de la política, no quería decir que entre ellos estuviesen «en una palabra, "los mejores"». En síntesis, «élite» o «clase» fueron en todas las maneras aquellos que se situaron por debajo de la figura del jefe del Estado. Los hombres $-\mathrm{y}$ las pocas mujeres que participaron-, fueron «élite» o «clase», mientras que todos los demás quedaron excluidos ${ }^{4}$.

Ahondar en el concepto de «élite» y no en el de «personal político» o de «clase política» se justifica en que los dos últimos conceptos aplicados a los hombres y mujeres de la dictadura suponen la dotación de un cierto grado de autonomía en el plano teórico. Una autonomía que ellos nunca tuvieron. En cambio, el concepto «élite» mezcla los que se pueden considerar tres planos de acción de los hombres de la dictadura: primeramente, tenían reputación (por el cargo que ocupaban); tenían poder de decisión (sobre el cómo y cuándo se tomaban las decisiones) y, finalmente, tenían derecho a un cargo por razón de su nombramiento por una jerarquía superior (razón por la que adquirieron la condición de políticos).

Sobre este principio, la historiografía incide en la idea de la entrada de una ingente masa de elementos no militantes en FE de las JONS; o FET de las JONS cuando se produjo la unificación. La carencia de individuos con militancia en el partido que funcionó como sustento ideológico de la dictadura sirvió para la entrada de hombres que fueron utilizados por las autoridades dictatoriales para ocupar cargos públicos. Hay estudios de la dictadura franquista en el ámbito local que destacan aumentos de militancia en FE de las JONS superiores a un 200\% entre el número de elementos activos con anterioridad a la guerra civil y después de ella ${ }^{5}$.

participaron en y de la política; es un concepto que proporciona al análisis una mayor maleabilidad y amplitud de miras respecto a los límites que pudiese presentar.

${ }^{4}$ Fue Miguel Jerez Mir, Élites políticas y centros de extracción en España (1938-1957). (Madrid: Centro de Investigaciones Sociológicas: 1982) quien realizó esta lectura en su estudio de los cargos políticos intermedios de la dictadura franquista. Después de hacer un repaso por el uso de los conceptos citados, Jerez Mir acaba por expresar la idea de que «élite» expresa una minoría rectora que se puede aplicar al caso de los municipios y las instituciones provinciales. Ejercer la política durante el franquismo fue, en todos los niveles, una cuestión de «minorías» escogidas por un poder superior o de «élite del poder».

5 Por citar algunos de los trabajos que remarcan esta línea: Manuel Requena Gallego, "Inmovilismo estructural y adaptación política del régimen franquista", coord. por Manuel Requena Gallego, Castilla- 
La entrada de elementos debe entenderse como un movimiento fruto del origen histórico de la propia dictadura. Nacida de una guerra civil que se extendió durante tres años, el fundamento cultural de la dictadura fue la existencia de una denominada «Victoria»; construida sobre la derrota de un enemigo político, social y cultural considerado, reiteradamente, el destructor de la nación española. Desde la posición de vencedores, los sublevados ejercieron su papel de dominadores sobre los vencidos ${ }^{6}$. Debido a la inexistencia de cuadros políticos suficientes dentro del partido, la dictadura habría actuado como un recogedor que tenía como único objetivo eliminar todas aquellas referencias a la política que se dio en España entre 1931 y julio de 1936. Una vuelta al orden social y político previo fundamentado en el control por parte de las clases sociales tradicionalmente dominantes ${ }^{7}$.

En un principio, la primigenia historiografía sobre FE de las JONS concluyó que el partido habría sido un movimiento minoritario durante la Segunda República, sin base social potente y propia que lo sustentase. De esa manera, se redujo el fascismo/falangismo previo a la guerra civil a una cuestión de élite juvenil $-\mathrm{y}$ no tan jóvenes monárquicos o simplemente reaccionarios provenientes de sectores derechistas radicalizados como el Bloque Nacional de Calvo Sotelo-, que no estaban cómodos participando en el juego democrático y que, faltos de un movimiento con potencia social para incidir en la política, decidieron pasar a la acción directa para marcar su ámbito de acción. Estas lecturas suelen obviar que el poder de un partido no depende de su presencia en las instituciones. La fuerza de un partido está en su capacidad de movilización social; y fue ahí donde FE de las JONS alcanzó su verdadero poder. El dominio posterior del partido único durante los primeros años de la dictadura, se sustentó en su capacidad de movilizar basándose en un discurso, una escenografía y una

La Mancha en el Franquismo, (Ciudad Real: Biblioteca Añil, 2003), 49-86, para el caso de Castilla-La Mancha; Ana Rosa Frías Rubio, Instituciones sorianas..., op. cit., pp. 646-647 refiriéndose a la provincia de Soria, donde se pasó de 24 afiliados a FE de las JONS antes de la guerra civil, a 1245 después producirse el golpe de Estado. Por último, Encarnación Barranquero Texeira, Málaga entre la guerra y la posguerra. (Málaga: Arguval, 1994) en el caso de Málaga, remarca que el peso del falangismo era tan bajo en la provincia, que el líder de este era un hombre de Sevilla.

6 Julián Casanova, "Una dictadura de cuarenta años", coord. por Julián Casanova, Morir, matar, sobrevivir. La violencia en la dictadura de Franco, (Barcelona: Crítica, 2004), 3-50.

${ }^{7}$ Borja de Riquer, “El «Nuevo Estado»...”, op. cit., pág. 16. 
coreografía social potentes $^{8}$. Hoy también es conocido que esa supuesta falta de militantes en los inicios del partido no es del todo cierta en algunas zonas de España 9 .

De ese extremo al de utilizar a los hombres con experiencia política municipal, una parte de la historiografia habla del mantenimiento de los hombres de la considerada «política de toda la vida» ${ }^{10}$. Como no había elementos suficientes se habría acudido a aquéllos denominados en los informes de la Guardia Civil o de FET de las JONS como «adictos no pertenecientes», «católico ferviente», «de derechas de toda la vida», «siempre perteneciendo a partidos de orden», etc. Fueron estos personajes de una pretendida ideología indefinida los que posteriormente construyeron la base política de la dictadura franquista ${ }^{11}$. El fenómeno de entrada de aluvión ha sido denominado por algunos historiadores como «travestismo político». A FET de las JONS habría acudido aquellos que buscaban su lugar en la vida política y económica de la España dictatorial. Pertenecer a Falange era la llave que abría la puerta a informes favorables, a favores personales, a un cargo en un ayuntamiento, a otro en la Diputación, a procurador, etc ${ }^{12}$.

Elementos que antes de militar en FET de las JONS lo habían hecho en la CEDA — con todas sus variantes regionales-; en Renovación Española o en el Partido Radical. La obligación coyuntural de dar entrada a individuos militantes de la derecha republicana se debió no sólo a la necesidad de construir un cuerpo efectivo en forma de

\footnotetext{
${ }^{8}$ Ferran Gallego, El evangelio fascista. La formación de la cultura política del franquismo. (Barcelona: Crítica, 2014). El papel de actor reducido a un pequeño núcleo social, pero con influencia en las calles, también lo describe de manera similar Julián Casanova, "La sombra del franquismo: ignorar la historia y huir del pasado", en Ángela Cenarro Lagunas, Julián Casanova y otros, El pasado oculto. Fascismo y violencia en Aragón (1936-1939), (Huesca: Mira editores, 1999), 1-28.

${ }^{9}$ Este extremo se comprueba en la obra clásica de Alfonso Lazo Díaz, Retrato del fascismo rural en Sevilla. (Sevilla: Universidad de Sevilla, 1998), y en textos más actuales que lo demuestran con nuevas fuentes como José Antonio Parejo Fernández, "Cuando fueron jóvenes... y fascistas", dir. por Fernando del Rey y Manuel Álvarez Tardío, Politicas del odio. Violencia y crisis en las democracias de entreguerras, (Madrid: Tecnos, 2017), 167-231.

10 Ángela Cenarro Lagunas, Cruzados y camisas azules: los orígenes del franquismo en Aragón. (Zaragoza: Prensas Universitarias de Zaragoza, 1997) para el caso de Aragón y María Cristina Rivero Noval, Política y sociedad en La Rioja durante el primer franquismo (1936-1945). (Logroño: Instituto de Estudios Riojanos, 2001) para el caso de La Rioja.

${ }^{11}$ La debilidad del partido se asocia al nacimiento de la dictadura por medio de una guerra civil. FET de las JONS no se desarrolló plenamente en el contexto en que lo hicieron el Partido Fascista Italiano o el Partido Nacionalsocialista alemán. Este elemento colocó sobre el tablero modos y lógicas diferentes. Esto produjo que «a pesar de que el falangismo tendiese a erigirse como referente ideológico oficial del régimen, no pudiera desplazar al resto de las tradiciones políticas que habían colaborado en tal victoria», Antonio Canales Serrano, Las otras derechas: derechas y poder local en el País Vasco y Cataluña en el siglo XX. (Madrid: Marcial Pons, 2006).

${ }^{12}$ El concepto de «travestismo político» fue utilizado por Martí Marín i Corbera, Els ajuntaments franquistes a Catalunya. (Lleida: Pagès editors, 2000).
} 
élite unificada; sino también por la necesidad de organizar el territorio que iba quedando en manos de los sublevados ${ }^{13}$.

La construcción fue extremadamente difícil para las autoridades de la dictadura. Además de los políticos «de siempre», entraron en el partido único la oligarquía y la clase adinerada, que utilizaron la estructura de la organización para conservar su poder $^{14}$. Esos elementos habrían situado a la dictadura en la posición de continuadora de la vieja política practicada en España; hincando los fundamentos de la construcción del sistema político dictatorial sobre los elementos de las élites de siempre:

Paradójicamente, la pretensión del régimen de pensar una Nueva España muy distinta de la decadente [...] de los siglos previos, se iba a basar en la presunta virginidad política del Movimiento y de sus militantes, lo que es rotundamente falso tanto para sus dirigentes más famosos como para sus cuadros menores ${ }^{15}$.

Ese fenómeno de continuidad es entendido por algunos historiadores españoles como la adaptación biográfica de los individuos a los tiempos donde el ideal fascista era el predominante. Dentro del partido se habrían encuadrado diferentes «familias políticas» que, a pesar de sus diferencias ideológicas, se unían en la defensa de un proyecto político consistente en «la negación de la democracia y sus consecuencias».

${ }^{13}$ Un caso paradigmático en la mezcla de composición clientelar y mantenimiento de elementos de la CEDA local (la Derecha Regional Valenciana), es el de Valencia y Castellón, estudiado por Andreu Ginés i Sànchez, La instauració del franquisme al País Valencià. (Valencia: Publicacions de la Universitat de València, 2010); un extremo confirmado anteriormente en algunas localidades de la región por Antonio Calzado Adaria y Ricardo Camilo Torres Fabra "La formación de un poder omnímodo: la Falange en la Ribera Baixa (1939-1945)", coord. por Javier Tusell y otros, El régimen de Franco. Congreso internacional, (Madrid: UNED, 1993), 29-40 y José Alberto Gómez Roda, Política i poder local. Catarroja: un municipi valencià durant el primer franquisme, (Catarroja: Afers, 1998). Agustín Millares Cantero, "Los monárquicos saludan a la romana. Notas sobre el primer franquismo grancanario", coord. por Aarón León Álvarez, El Franquismo en Canarias, (Santa Cruz de Tenerife: Lecanarien ediciones, 2014), 108-145, demuestra que, ante la falta de elementos propios falangistas, el partido en Las Palmas de Gran Canaria estaba dirigido por un joven que non era, precisamente, una «lumbrera intelectual».

${ }^{14}$ Andreu Ginés i Sànchez, La instauració del franquisme..., op. cit., pág. 85.

15 Antonio Cazorla Sánchez, Desarrollo sin reformistas. Dictadura y campesinado en el nacimiento de una nueva sociedad en Almería (1939-1975). (Almería: Instituto de Estudios Almerienses, 1999). En la misma línea que este autor sigue Óscar Rodríguez Barreira, Miserias del poder: los poderes locales y el nuevo estado franquista. (Valencia: Publicacions de la Universitat de València, 2013). Autores como Francisco Cobo Romero y Teresa María Ortega López, Franquismo y posguerra en Andalucía oriental. Represión, castigo a los vencidos y apoyos sociales al régimen franquista (1936-1950). (Granada: Universidad de Granada, 2005) estudiando las zonas rurales de la Andalucía oriental, presenta a esos continuadores del fenómeno caciquil como oligarcas en búsqueda de perpetuar su dominio social. Según la investigación de los autores, eran un colectivo diversificado, a los que unía una premisa fundamental: todos se habían visto amenazados por las reformas de la Segunda República. 
Un proyecto que actuó con la finalidad de «imponer un determinado modelo social» ${ }^{16}$. Por ello, con la idea de la existencia de las denominadas «familias políticas» dentro de FET de las JONS - procedentes de los partidos de derechas anteriores al golpe de Estado de julio de 1936-, y con una cultura política que en principio no deferiría de la propia de la época de la Restauración borbónica, finalizó el nacimiento del denominado proceso de fascistización de las élites políticas de la derecha española.

La fascistización de los políticos conservadores fue el proceso que los llevó a adoptar elementos del fascismo, pero sin convertirse en fascistas plenos. Fue la fascistización lo que habría permitido a estos individuos continuar sus trayectorias políticas con posterioridad a septiembre de 1945. Ello quiere decir que las élites políticas que, según los estudios, se presentaron en julio de 1936 pudieron pervivir gracias a la mezcla de elementos discursivos fascistas con otros más «versátiles»o, simplemente, de derechas ${ }^{17}$.

En resumen, la trayectoria por la construcción de la dictadura franquista a nivel local define la imagen de una élite política donde se mezclaron diferentes orígenes político-culturales. Su procedencia del espectro político-cultural conservador — bien reaccionario, bien de corte liberal—, ha ayudado a conservar esa idea de continuidad con la tradición anterior. A pesar de esa idea de continuidad por el hecho de tener los mismos orígenes, en este estudio pretendemos abrir un interrogante sobre la idea de que la dictadura franquista en su ámbito local fue una mera restauración del fenómeno caciquil o de coexistencia dentro del partido único de diferentes «familias políticas». Para ello, se analizan los nombres de los hombres que fueron alcaldes, gestores y concejales desde 1917 hasta 1951.

\section{METODOLOGÍA}

Para realizar este estudio se han extraído los nombres de los concejales y gestores de los libros de actas de los Plenos municipales de las ciudades de A Coruña,

\footnotetext{
${ }^{16}$ Carme Molinero, "Present i futur de la historiografia sobre el règim franquista", dir. Jordi Font Agulló, Història i memoria: el franquisme i els seus efectes als Països Catalans, (Valencia: Publicacions de la Universitat de València, 2007), 285-301.

${ }^{17}$ La teorización sobre la tendencia fascistizadora fue desarrollada de manera integral por Ismael Saz, Fascismo y franquismo. (Valencia: Publicacions de la Universitat de València, 2004), entre otras de sus obras sobre la dictadura franquista.
} 
Ferrol, Santiago de Compostela, Lugo, Ourense, Pontevedra y Vigo. Las series se inician en el año 1917 como punto clave en la transformación de cultura política de la derecha española con motivo de la Revolución rusa; y finalizan en el año 1951, cuando se celebran las segundas elecciones por tercios de la «democracia orgánica» en el ámbito municipal ${ }^{18}$.

Para analizar los datos obtenidos se establecieron cuatro etapas delimitadas por las disposiciones legales que afectaron al ámbito de los municipios dictadas por las autoridades de la dictadura. La primera etapa abarca de julio de 1936 a octubre de 1937, donde se utilizaba el Estatuto Municipal de 1924, la Ley Municipal de 1935 y las disposiciones en materia de régimen local de la Restauración. En octubre de 1937 apareció la primera de las disposiciones que afecta al procedimiento de composición de las gestoras municipales dictatoriales ${ }^{19}$. La segunda etapa abarcaría de esa fecha de 1937 a julio de 1945, cuando se publicó la Ley de Bases de Régimen Local de la dictadura - la norma que fijó el funcionamiento de los municipios hasta el final de esta $^{20}$. Desde julio de 1945 a noviembre de 1948 consideramos la tercera etapa al celebrarse en la última fecha las primeras elecciones de la denominada «democracia

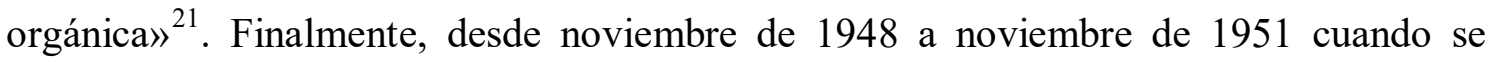
produjeron las segundas elecciones «orgánicas».

Teniendo en cuenta el recorrido desde 1917 el trabajo con las fuentes consiste en extraer una relación de alcaldes, gestores y concejales de los siete municipios sobre los que se construye este estudio. En total son 2237 personas registradas en la base de datos, con sus correspondientes fechas de nombramiento y de cese, así como su profesión y filiación política previa y posterior al golpe de Estado de julio de 1936 — siempre que fue posible adscribirlos.

En cada etapa se nombró a un número total de alcaldes, concejales y gestores municipales, debiendo considerar los nombramientos y los ceses que se produjeron en

\footnotetext{
${ }^{18}$ Sobre los cambios que operan en España con el estallido revolucionario de 1917, sirva como ejemplo la consulta de la obra colectiva de Eduardo González Calleja, (coord.), Anatomía de una crisis. 1917 y los españoles. (Madrid: Alianza Editorial, 2017).

19 “Orden de 30 de octubre de 1937”, BOE, 3 de noviembre de 1937.

20 “Ley de Bases de Régimen Local de 17 de julio de 1945”, BOE, 18 de julio de 1945.

21 "Decreto de 30 de septiembre de 1948 por el que se dan normas para la celebración de las elecciones municipales" y "Decreto de 30 de septiembre de 1948 por el que se convocan elecciones municipales", BOE, 7 de octubre de 1948.
} 
cada uno de estos. Es sobre ese número total de concejales del que se obtiene el porcentaje de continuidad de los elementos de la élite política que venían actuando con anterioridad a julio de 1936. La procedencia cronológica es el elemento discriminador que permite arrojar los datos que sustentan este estudio.

\section{LA CONFIGURACIÓN DE LAS ÉLITES URBANAS GALLEGAS}

A la luz de los resultados obtenidos a través del estudio de la base de datos elaborada se pueden obtener algunas claves interpretativas del proceso de construcción de las élites políticas locales en el ámbito de las ciudades gallegas en la dictadura franquista. En primer lugar, se observa el uso de hombres con una determinada experiencia política anterior al golpe de Estado de julio de 1936. Estos hombres iniciaron su adscripción ideológico-cultural a los postulados del futuro Movimiento en ese momento anterior. La entrada en la actividad política local fue el punto de arranque de una determinada cultura política asociada a la dictadura en ciernes. Pero ya desde ese momento iniciático también se observa un peso específico destacable de aquellos que carecían de un pasado político previo al golpe de Estado en el ámbito municipal.

En segundo lugar, el estudio de las series de alcaldes y gestores municipales - y en aquellos casos conocidos-, permite conocer los lugares de extracción socioprofesional preferidos por las autoridades que hacían la selección de los miembros de las corporaciones. Viendo los datos se observa que las autoridades se inclinaron por aquellos hombres que tenían un medio de sustento: desde propietarios de industrias o terrenos, hasta catedráticos de instituto. Así, un primer análisis de la base de datos manifiesta un binomio de causas que define a los elementos de la primera élite política local en las ciudades estudiadas: un determinado grado de experiencia política sumado a una posición económica desahogada. Este factor no es despreciable, ya que durante los primeros años de la dictadura los cargos municipales carecían de retribución por razón de su actividad política.

En los primeros años se observa el recurso al nombramiento de militares. En las primeras horas y días, las autoridades militares sublevadas en Galicia nombraron a miembros del ejército para ocupar los puestos de gestores municipales y alcaldes. Con el estamento militar local figuran los elementos de la pequeña burguesía propietaria: 
comerciantes, empleados y profesionales liberales. Esta mezcla no difiere en exceso de lo ya conocido en otros lugares de España ${ }^{22}$.

\section{Gráfico 1: Alcaldes, gestores y concejales de las ciudades estudiadas por extracción socioeconómica}

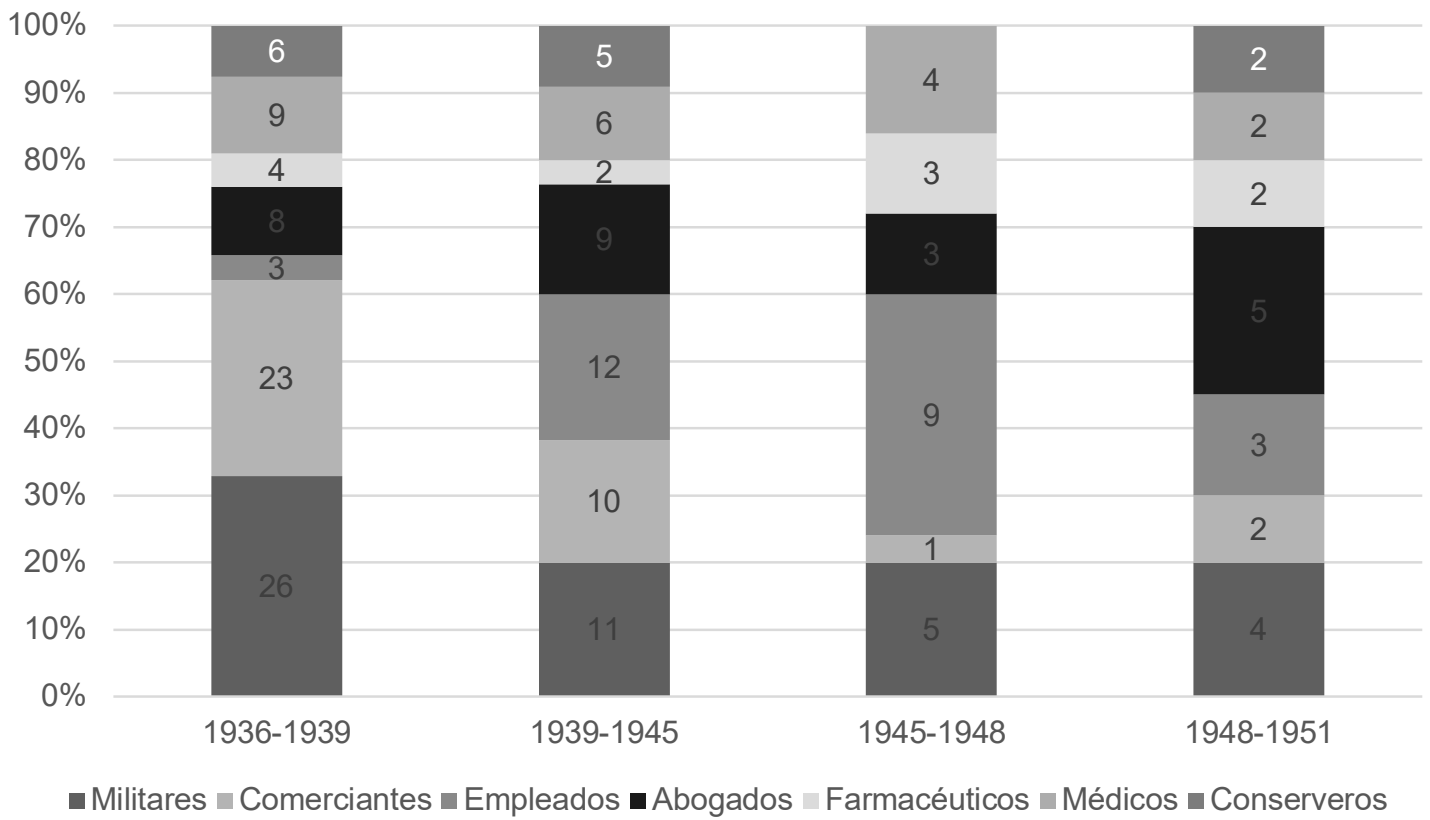

Fuente: Elaboración propia a partir de la información recogida en los Libros de actas de los Plenos municipales de las ciudades estudiadas.

A la hora de detallar el origen cronológico de los primeros alcaldes y gestores municipales nombrados por las autoridades sublevadas en el momento de hacerse con el

\footnotetext{
${ }^{22}$ La mezcla de militares y otros miembros de la pequeña burguesía local la describen también Agustín Millares Cantero, "Los monárquicos...", op. cit., pp. 108-145, cuando habla de la composición de la Falange grancanaria como una mezcla de elementos de las hermandades católicas y de hombres de derechas, precisamente éstos, grandes terratenientes o profesionales liberales. En la misma línea, lo describió para Murcia Nicolás Marín, Instituciones murcianas..., op. cit., pp. 286-292 cuando define el aumento de los profesionales liberales frente a los militares con el paso progresivo del tiempo. En el caso de Málaga, Matilde Eiroa San Francisco, Viva Franco: hambre, racionamiento, falangismo: Málaga, 1939-1942, (Málaga: Artes gráficas Aprisa, 1995) describe que el poder local quedó en manos de los terratenientes y de las élites locales de comerciantes, funcionarios, ingenieros y profesionales liberales; además de la cuota que les correspondía a los militares. Un estudio más actualizado y con fuentes no trabajadas anteriormente por aquellas que abrieron el camino en la investigación de la implantación de la dictadura en la ciudad de Málaga es el de Cristian Matías Cerón Torreblanca, "La paz de Franco", la posguerra en Málaga: desde los oscuros años 40 a los grises años 50, (Málaga: Universidad de Málaga, 2007). Tendencias similares fueron descritas por Julián Sanz Hoya, La construcción de la dictadura franquista en Cantabria. Instituciones, personal político y apoyos sociales (1937-1951), (Santander: Ediciones de la Universidad de Cantabria, 2009) para el caso de Cantabria; Ciudad Real, por Damián Alberto González Madrid, La Falange manchega (1939-1945). Política y sociedad en Ciudad Real durante la etapa «azul» del primer franquismo, (Ciudad Real: Diputación de Ciudad Real, 2004); o para Valencia y Castellón por Andreu Ginés i Sànchez, La instauració del franquisme..., op. cit., pp. 126-128.
} 
control de las ciudades, se observan unas líneas comunes entre todos ellos. En primer lugar, para la etapa entre julio de 1936 y octubre de 1937, se observa el extraordinario peso dado a aquellos que ya habían ejercido con anterioridad al golpe de Estado un cargo municipal. El caso paradigmático es el de la ciudad de Lugo, donde de los 8 gestores de la etapa la mitad ya fueran nombrados en la dictadura de Primo de Rivera. Una tendencia que también siguió la ciudad de Santiago, en la que fueron designados un mayor número de gestores. En otras urbes, como Ourense, las autoridades sublevadas se inclinaron por aquellos que habían ejercido en la corporación republicana dada la especial naturaleza de la élite política conservadora de la ciudad; situada en el núcleo del ámbito de acción del calvosotelismo ${ }^{23}$.

Tabla 1: Gestores de la dictadura franquista procedentes de períodos políticos anteriores a julio de 1936-octubre de 1937

\begin{tabular}{|l|c|c|c|c|c|c|}
\hline & $\begin{array}{c}\mathrm{N}^{\circ} \mathrm{de} \\
\text { gestores }\end{array}$ & $\underline{\text { \% Restauración }}$ & $\underline{\text { \% P. de Rivera }}$ & $\underline{\text { \% Dictablanda }}$ & $\frac{\text { \% República }}{\text { abril 1931 }}$ & $\begin{array}{c}\text { \% República } \\
\text { octubre 1934 }\end{array}$ \\
\hline ACO & 24 & - & $28,83 \%$ & - & - & - \\
\hline STG & 32 & $6,25 \%$ & $43,75 \%$ & - & $6,25 \%$ & - \\
\hline FRL & 27 & $3,70 \%$ & $7,41 \%$ & $7,41 \%$ & - & $3,70 \%$ \\
\hline LUG & 8 & - & $50 \%$ & - & - & - \\
\hline OUR & 20 & $15 \%$ & $10 \%$ & - & $25 \%$ & $5 \%$ \\
\hline PON & 21 & $4,76 \%$ & $14,29 \%$ & $9,52 \%$ & - & $9,52 \%$ \\
\hline VIG & 31 & $3,23 \%$ & $25,81 \%$ & $9,68 \%$ & $3,23 \%$ & $3,23 \%$ \\
\hline Total & 163 & $4,91 \%$ & $23,31 \%$ & $4,29 \%$ & $4,91 \%$ & $3,07 \%$ \\
\hline
\end{tabular}

Fuente: Elaboración propia a partir de las series de Libros de actas de los Plenos municipales de las ciudades estudiadas.

En vista de lo expuesto en la Tabla 1, surgen dos ideas a destacar. En primer lugar, en los primeros compases de la construcción de la dictadura franquista las autoridades sublevadas se inclinaron - en líneas generales en las siete ciudades estudiadas-, por aquellos hombres que contaban con experiencia en la gestión local durante el período primorriverista. En segundo lugar, que un 40,49\% de los 163 gestores

\footnotetext{
${ }^{23}$ Sobre el papel de Calvo Sotelo en la configuración de la derecha local ourensana, véase Julio Prada Rodríguez, A dereita politica ourensá: monárquicos, católicos e fascistas (1934-1937), (Ourense: Servizo de Publicacións da Universidade de Vigo, 2005).
} 
nombrados provenía de tradiciones políticas anteriores al golpe de Estado de julio de 1936, siendo un 59,51\% de los nombrados hombres sin pasado político previo a esa fecha $^{24}$.

La etapa de octubre de 1939 a julio de 1945 alumbra dos hechos clave en la construcción de la dictadura en el ámbito local. Primero, es la fase de aclimatación de las nuevas autoridades a la realidad política, económica, social y cultural del territorio; el momento de la adaptación y consolidación del poder local. Segundo, es la fase donde se elaboran las disposiciones legales que regularon los mecanismos de nombramiento de los alcaldes y gestores; así como del número de integrantes de cada corporación en función de su población. Es, en definitiva, la atapa en la que la dictadura franquista vivió los altibajos de la evolución de un panorama internacional dominado por la Segunda Guerra Mundial. El devenir del contexto internacional condicionó el paso de una dictadura próxima al fascismo hacia otra que pretendió camuflar su autoritarismo con la invención de una modalidad nueva de democracia con pretendida naturaleza viva: la «democracia orgánica».

Fruto de estos cambios, las élites fueron adaptándose al nuevo ambiente de postguerra civil en cada una de las ciudades. En vista del análisis de los datos obtenidos, después de utilizar hombres con trayectoria política previa, las autoridades parecieron concluir que no podían continuar echando mano de aquellos que habían ejercido el poder como una herramienta para crear redes políticas que pudiesen favorecer o instigar disonancias internas en la administración local.

Tabla 2: Gestores de la dictadura franquista procedentes de períodos políticos anteriores a octubre de 1937-julio de 1945

\begin{tabular}{|c|c|c|c|c|c|c|c|}
\hline & $\begin{array}{l}\frac{\mathrm{N}^{\circ} \mathrm{de}}{\text { gestores }} \\
\text { ger }\end{array}$ & $\begin{array}{c}\frac{\%}{0} \\
\text { Restauración } \\
\end{array}$ & $\begin{array}{c}\frac{\%}{0} \\
\text { P. de Rivera }\end{array}$ & \% Dictablanda & $\frac{\text { \% República }}{\underline{\text { abril } 1931}}$ & $\begin{array}{c}\text { \% República } \\
\text { oct. } 1934\end{array}$ & $\begin{array}{l}\text { \% Dictadura jul. } \\
\underline{1936 \text {-oct. } 1937}\end{array}$ \\
\hline ACO & 59 & - & $10,17 \%$ & $1,69 \%$ & - & $3,39 \%$ & $35,59 \%$ \\
\hline STG & 46 & - & $6,52 \%$ & - & - & - & $17,39 \%$ \\
\hline FRL & 30 & - & - & - & - & - & $53,33 \%$ \\
\hline LUG & 47 & $2,13 \%$ & $14,89 \%$ & - & - & $4,26 \%$ & $8,51 \%$ \\
\hline
\end{tabular}

\footnotetext{
${ }^{24}$ María Jesús Souto Blanco, Los apoyos al régimen franquista en la provincia de Lugo (1936-1940), (Sada: Ediciós do Castro, 1999) que realizó uno de los primeros estudios en el ámbito gallego sobre las élites políticas de la dictadura en la ciudad de Lugo, concluyó con una idea recurrida en otros estudios: las primeras gestoras de la dictadura, al recurrir a elementos de la tradición restauracionista y primorriverista fueron simples continuadoras de esas dos tradiciones.
} 
Adrián Presas Sobrado

La configuración de las élites políticas urbanas gallegas en el primer franquismo (1936-1951)

\begin{tabular}{|l|c|c|c|c|c|c|c|}
\hline OUR & 54 & $3,70 \%$ & $5,56 \%$ & - & $9,26 \%$ & - & $7,41 \%$ \\
\hline PON & 56 & - & $5,36 \%$ & - & - & $3,57 \%$ & $28,57 \%$ \\
\hline VIG & 66 & - & $3,03 \%$ & - & $1,52 \%$ & - & $16,67 \%$ \\
\hline Total & 358 & $0,84 \%$ & $6,70 \%$ & $0,28 \%$ & $1,68 \%$ & $1,68 \%$ & $22,35 \%$ \\
\hline
\end{tabular}

Fuente: Elaboración propia a partir de las series de Libros de actas de los Plenos municipales de las ciudades estudiadas.

Así se ve en la Tabla 2: el número de concejales con pasado político previo al golpe de Estado de julio de 1936 pasó a ser del 11,18\%; mientras que el 22,35\% continuaron de aquellas primeras gestoras nombradas por los sublevados. La diferencia de esos dos porcentajes con el total es que el $66,47 \%$ de los gestores nombrados en ese período no tenían experiencia política previa.

Este resultado nos inclina hacia la idea de que pocos años después de su imposición la dictadura franquista estaba seleccionando a hombres de la élite de las ciudades con la condición determinante de carecer de experiencia política. Las autoridades de la dictadura buscaban y nombraban - ya en su inicio-, a aquellos que respondían a la jerarquía de las autoridades. Una ciudad como Ferrol vio como sus gestoras fueron configuradas con una proporción de un 53,33\% de hombres procedentes de las gestoras nombradas después de julio de 1936 , y de un $46,67 \%$ de elementos sin experiencia política previa. Aquellos que no tenían experiencia se mezclaban con elementos como el alcalde Eduardo Ballester Peris o con gestores con una larga tradición política como Francisco Montenegro Cabezas. En Pontevedra, se primó la experiencia de hombres como Casiano Peláez Merino o Celestino Fontoira Peón, que se convirtieron en habituales en las corporaciones municipales de la capital pontevedresa. Lo mismo sucedió en A Coruña con los alcaldes José Pérez Ardá y Alfonso Molina Brandao; o los gestores Jorge Ozores Arraiz o Jacobo Conde Castilla.

Tabla 3: Gestores de la dictadura franquista procedentes de períodos políticos anteriores a julio de 1945-noviembre de 1948

\begin{tabular}{|c|c|c|c|c|c|c|c|c|}
\hline & $\begin{array}{l}\frac{\mathrm{N}^{\circ} \mathrm{de}}{\text { gestores }} \\
\text { ges }\end{array}$ & $\begin{array}{c}\underline{\%} \\
\text { Restauración } \\
\end{array}$ & $\frac{\text { \% P.de }}{\underline{\text { Rivera }}}$ & $\begin{array}{c}\frac{\%}{\underline{0}} \\
\text { Dictablanda }\end{array}$ & $\begin{array}{c}\frac{\%}{\%} \\
\text { República } \\
\underline{\text { abril } 1931}\end{array}$ & $\begin{array}{c}\frac{\%}{\%} \\
\text { República } \\
\text { oct. } 1934\end{array}$ & $\frac{\underline{\text { \% Ditadura }}}{\text { jul. 1936-oct. }} \frac{1937}{\underline{1937}}$ & $\begin{array}{c}\frac{\text { \% Ditadura }}{\text { oct. 1937-jul. }} \\
\underline{1945}\end{array}$ \\
\hline ACO & 50 & $2 \%$ & $2 \%$ & - & - & $2 \%$ & $2 \%$ & $70 \%$ \\
\hline STG & 32 & - & - & - & - & - & $6,25 \%$ & $40,63 \%$ \\
\hline FRL & 31 & - & $3,23 \%$ & - & - & - & $6,45 \%$ & $96,77 \%$ \\
\hline LUG & 21 & $9,52 \%$ & $9,52 \%$ & - & - & $9,52 \%$ & - & $61,90 \%$ \\
\hline
\end{tabular}


Adrián Presas Sobrado

La configuración de las élites políticas urbanas gallegas en el primer franquismo (1936-1951)

\begin{tabular}{|c|c|c|c|c|c|c|c|c|}
\hline OUR & 18 & - & $3,57 \%$ & - & - & - & $3,57 \%$ \\
\hline PON & 19 & - & - & - & - & $5,26 \%$ & - & $63,43 \%$ \\
\hline VIG & 27 & - & - & - & - & - & $-16 \%$ \\
\hline Total & 208 & $1,44 \%$ & $2,40 \%$ & - & - & $1,92 \%$ & $2,88 \%$ & $62,59 \%$ \\
\hline
\end{tabular}

Fuente: Elaboración propia a partir de las series de Libros de actas de los Plenos municipales de las ciudades estudiadas.

En las dos etapas siguientes la tónica se mantuvo inalterada. Es lo que se observa en la etapa comprendida entre la aprobación de la Ley de Bases del Régimen local en julio de 1945 y las primeras elecciones de la «democracia orgánica» en noviembrediciembre de 1948. Para el total de las ciudades el número de gestores procedente de períodos anteriores al golpe de Estado de julio de 1936 se reduce a un 5,76\% de los 208 gestores nombrados en ese período de la dictadura franquista. E1 70,67\% de los gestores continuaban o habían sido nombrados de nuevo después de julio de 1936. Esto deja en un 23,57\% el total de gestores sin experiencia de gestión política previa a julio de 1936 . En el período comprendido entre julio de 1945 y noviembre de 1948 debemos los cambios como movimientos de las autoridades provinciales encaminados a preparar el cambio de las gestoras municipales hacia la figura de las corporaciones. El proceso de cambio se desarrolló sobre los elementos con experiencia de gestión en la propia dictadura franquista ${ }^{25}$.

La etapa iniciada con las elecciones por tercios de noviembre-diciembre de 1948 parece haber determinado aún más la existencia de una élite adaptada a la dictadura franquista en las ciudades estudiadas. Las dos primeras convocatorias de la «democracia orgánica» significan la consolidación de lo que se supone una dinámica renovadora continua entre las propias élites políticas urbanas. Sobre el total de los 150 concejales que fueron nombrados entre diciembre de 1948 y diciembre de 1951, un 24,67\% había participado con anterioridad en la política municipal de la dictadura. Al sumar a ese porcentaje el de aquellos con experiencia política previa a la dictadura franquista, entre todos representan un $38,67 \%$ del total. La élite se fue renovando con la «democracia orgánica» en los ámbitos electorales del «tercio de cabezas de familia» y el «tercio

${ }^{25}$ El estudio de la Andalucía oriental de Francisco Cobo Romero y Teresa María Ortega López, Franquismo y posguerra en Andalucía oriental..., op. cit., pág. 237 indica que en las ciudades ocuparon los cargos de alcaldes y gestores «antiguos militantes de derechas que no dudaron en ofrecer su apoyo», se entiende que económico y político, a la causa de los sublevados. Sobre las pretendidas elecciones en la dictadura véase el artículo de Carlos Domper Lasús, "El franquismo a través de las urnas. Metodología, fuentes y retos para una aproximación electoral al régimen de Franco", Politica y sociedad, 55, 1, (2018): 115-134. 
sindical»; con un movimiento especialmente intenso en el segundo. El «tercio de entidades» quedaba fuera de la dinámica, al ser competencia de los gobernadores civiles la selección de los candidatos.

Tabla 4: Concejales de la dictadura franquista procedentes de períodos políticos anteriores a noviembre de 1948-noviembre de 1951

\begin{tabular}{|c|c|c|c|c|c|c|c|c|c|}
\hline & $\begin{array}{c}\frac{\mathrm{N}^{\mathrm{o}} \mathrm{de}}{} \\
\text { concejales }\end{array}$ & $\begin{array}{c}\stackrel{\%}{0} \\
\text { Restauración }\end{array}$ & $\frac{\% \text { P. de }}{\underline{\text { Rivera }}}$ & $\begin{array}{c}\frac{\%}{0} \\
\text { Dictablanda }\end{array}$ & $\begin{array}{c}\frac{\stackrel{\%}{0}}{\text { República }} \\
\frac{\text { abril de }}{\underline{1931}}\end{array}$ & $\begin{array}{c}\frac{\%}{0} \\
\text { República } \\
\underline{\text { oct. de } 1934} \\
\end{array}$ & $\begin{array}{l}\text { \% Dictadura } \\
\text { jul. 1936- } \\
\text { oct. 1937 }\end{array}$ & $\frac{\text { \% Dictadura }}{\frac{\text { oct.. 1937- }}{\text { jul. } 1945}}$ & $\begin{array}{l}\text { \% Dictadura } \\
\text { jul. 1945- } \\
\underline{\text { nov. } 1948}\end{array}$ \\
\hline ACO & 22 & - & $4,55 \%$ & - & - & $4,55 \%$ & - & $13,64 \%$ & $22,73 \%$ \\
\hline STG & 21 & - & $4,76 \%$ & - & - & - & - & $4,76 \%$ & $19,05 \%$ \\
\hline FER & 22 & $4,55 \%$ & $9,09 \%$ & - & - & - & - & $13,64 \%$ & $9,09 \%$ \\
\hline LUG & 21 & $9,52 \%$ & $4,76 \%$ & - & - & $9,52 \%$ & - & - & $9,52 \%$ \\
\hline OUR & 21 & - & - & - & - & & $4,76 \%$ & $9,52 \%$ & $33,33 \%$ \\
\hline PON & 21 & - & $9,52 \%$ & - & - & $19,05 \%$ & - & $9,52 \%$ & - \\
\hline VIG & 22 & - & $18,18 \%$ & - & - & - & & $13,64 \%$ & $9,09 \%$ \\
\hline Total & 150 & $2 \%$ & $7,33 \%$ & - & - & $4,67 \%$ & $0,67 \%$ & $9,33 \%$ & $14,67 \%$ \\
\hline
\end{tabular}

Fuente: Elaboración propia a partir de las series de Libros de actas de los Plenos municipales de las ciudades estudiadas.

La composición de las gestoras y corporaciones municipales se consolidó en noviembre-diciembre de 1948. El mantenimiento de los hombres y del estilo político se expresó en lo comedido de los discursos de los alcaldes después de las tomas de posesión correspondientes. En la «etapa azul» de la dictadura era frecuente que los alcaldes nombrados se acordasen, por ejemplo, del militante Juan Canalejo «de apellido glorioso para todos los falangistas coruñeses» ${ }^{26}$. Los alcaldes, puestos al mando por los superiores jerárquicos, aleccionaban a los gestores exigiéndoles «perseverancia en el trabajo»; y recordándoles que habían formulado un juramento al ingresar en Falange. En él se resaltaban los valores de la «unión y unidad de acción, dejando a un lado amor propio y apasionamientos». El gestor municipal merecía «el beneplácito y la confianza del Mando, y no se debe olvidar que las censuras dirigidas a ellos o el entorpecimiento a

\footnotetext{
${ }^{26}$ Pleno do Concello da Coruña. Libro de Actas do Pleno do Concello da Coruña, 1943, AMC, Concello da Coruña, Goberno, Libros de Actas, Caja 168, fol. 131. Los actos de adhesión al Movimiento y a sus directores fueron frecuentes en las ciudades desde julio de 1936. Como ejemplo, en el Pleno do Concello da Coruña. Libro do Actas do Pleno do Concello da Coruña, 1936, AMC, Concello da Coruña, Goberno, Libros de Actas, Caja 166, fol. 188, se nombró hijo adoptivo de la ciudad a Francisco Franco y se daba su nombre a la Praza da Constitución, por ser el símbolo de «la salvación de la Patria, que renace redimida por su propio esfuerzo para una nueva era de paz, de trabajo, de disciplina y de encumbramiento».
} 
su labor, es censura al Mando, ya que por estos son propuestos a la Superioridad y por aquel nombrados»» 27 .

Era también frecuente que los jefes provinciales del Movimiento arengasen a los nombrados recordándoles a todos que:

[...] estáis persuadidos de que a los cargos no se viene a presumir, sino a trabajar, y que con vuestro trabajo haréis saber que aquí no hay más que una Autoridad, una dirección: el Alcalde; unos brazos: los Tenientes de Alcalde y los Concejales, y unas manos: los empleados municipales. A todos, pues, exijo lealtad, celo y disciplina en los servicios. Como representantes del Estado y del Partido, así lo exijen [sic] el Gobernador Civil y el Jefe Provincial de la Falange, para el mejor servicio de La Coruña y de España, teniendo como garantía para ello todos los Gestores saberse respaldados por las Autoridades Politicas y Administrativas ${ }^{28}$.

Con el avance de la Segunda Guerra Mundial, los ayuntamientos comenzaron a rendir homenajes al dictador. Se imbuyeron de la necesidad nacida de las jerarquías de Madrid de apoyar a Franco en un momento en el que los dos espejos internacionales en los que se había mirado se estaban rompiendo. Sirva como ejemplo el nombramiento del dictador - por aclamación de los gestores reunidos-, como «Alcalde Perpetuo» de la ciudad de Santiago de Compostela ${ }^{29}$. Cuando la derrota del Eje en la Segunda Guerra Mundial era ya un hecho, los consistorios gallegos se apresuraron a reafirmar su adhesión a Franco concediéndole medallas. En Vigo, por ejemplo, le fue dada una medalla de platino, creada por el consistorio en octubre de 1936 para «premiar méritos extraordinarios contraídos en favor de la ciudad». En el caso de Franco, el ayuntamiento se la concedió por la «constante preocupación» del dictador por los problemas que afectaban a la ciudad olívica ${ }^{30}$.

De ahí se pasó a alcaldes que se despedían de su cargo con el «temor de que se pueda romper la estrecha solidaridad que durante ocho años y cinco meses, que exactamente se cumplen hoy, ha unido a los miembros de la Gestora con su presidente».

\footnotetext{
${ }^{27}$ Libro de Actas do Pleno do Concello de Ourense, 1938-1941, AMOu, Concello de Ourense, Goberno, Libros de Actas, fol. 183.

${ }^{28}$ Palabras del Jefe provincial del Movimiento de A Coruña, Lorenzo Vilallonga, en Pleno do Concello da Coruña. Libro de Actas do Pleno do Concello da Coruña, 1940, AMC, Goberno, Libros de Actas, Caja 167, fol. 110.

${ }^{29}$ Libro de Actas do Pleno do Concello de Santiago, 1943, AHU-USC, Arquivos Municipais, Concello de Santiago, Libros de Actas, AM 2390, fol. 103.

${ }^{30}$ Libro de Actas do Pleno do Concello de Vigo, 1945, AMV, Concello de Vigo, Goberno, Libros de Actas, PLE-188, fol. 280.
} 
O alcaldes que llegaban al cargo expresando los deseos de «[...] obtener la colaboración de los nuevos Concejales, manifestando que las pequeñas pasiones que pudieran existir, deben dejarse a la puerta de la Casa Consistorial, en donde se debe entrar solamente con el propósito de colaborar para el bien de los intereses municipales ${ }^{31}{ }^{3}$.

Las alteraciones del estilo en la manera de manifestarse es otro ejemplo de los cambios introducidos en los hombres de las élites políticas locales. Una transformación del modo condicionada por la coyuntura política nacional e internacional — como fue la evolución de la Segunda Guerra Mundial. La cualidad de falangista continuó presente; pero la manera de manifestarla mudó a un estilo más ligero. Esas elecciones de 1948 prepararon el camino para la estabilización de las élites de la dictadura franquista en el ámbito local. Se produjo una mezcla de experiencia y novedad que los gobernadores civiles aprovecharon para configurar las candidaturas electorales y, también, condicionar el devenir futuro de las corporaciones urbanas, especialmente en el tercio de entidades.

\section{LA PERSISTENCIA DE LAS IDEAS FUERZA EN EL PROCESO DE CONFIGURACIÓN DE LAS ÉLITES POLÍTICAS URBANAS}

Creemos que el análisis diacrónico del origen cronológico de los gestores y concejales nombrados por la dictadura para configurar los ayuntamientos de las siete ciudades estudiadas pone en cuestión la idea de la dictadura franquista como continuadora del fenómeno caciquil previo. Sobre la base teórica fijada en las evidencias documentales en la recurrencia — por parte de las autoridades políticas de la dictadura-, a elementos políticos de tradición liberal, se acabó por construir un marco común analítico historiográfico que pivota sobre el principio del peso del fenómeno de la recuperación, desarrollo y consolidación de las élites políticas locales españolas por el régimen dictatorial.

Una parte de la historiografía sobre la construcción de la dictadura franquista a nivel local consolidó la idea de que existe una continuación con la dinámica

\footnotetext{
${ }^{31}$ Las citas anteriores se encuentran en Libro de Actas do Pleno do Concello de Ferrol, 1947, AMF, Concello de Ferrol, Goberno, Concello Pleno, Libros de Actas de sesión do Pleno, 132, fol. 9 y Libro de Actas do Pleno do Concello de Ferrol, 1949, AMF, Concello de Ferrol, Goberno, Concello Pleno, Libros de Actas de sesión do Pleno, 132, fol. 36.
} 
restauracionista $\mathrm{y}$, consecuentemente, del ideal del caciquismo de aquella etapa. Tanto la idea de la conservación como de la renovación de ese fenómeno político —en un nuevo marco sociopolítico como fue el de la dictadura-, son fundamentales para entender la elaboración de esa posición teórica historiográfica.

Esta perspectiva elude los cambios producidos por la crisis política de las dos primeras décadas del siglo XX. Los movimientos políticos que apostaban por el reconocimiento de una mayor autonomía de las nacionalidades que integran España, pusieron en tensión el régimen de la Restauración. Los elementos políticos que sostenían aquél se dividieron en dos ramas, diferentes según los mecanismos de reforma política propuesta. Por un lado, existió una política que pretendía la reforma del sistema desde dentro - los partidos del turno - ; y del otro lado, aquellos que apostaban por la desaparición completa del sistema — sectores de los partidos turnistas, socialistas, catalanistas, anarquistas, etc. Catalanistas, socialistas o republicanos aumentaron su presencia en el Congreso de los Diputados alejando a las fuerzas políticas del turno de gobiernos estables. Lo mismo sucedía en las grandes urbes, donde se notaba el aumento de las fuerzas políticas que se habían mantenido ajenas al turno restauracionista. Reacciones como la de Cambó reuniendo a los diputados catalanes en una Asamblea en Barcelona son un ejemplo del proceso de descomposición política que se vivía en la España de inicios del siglo $\mathrm{XX}^{32}$.

España no era ajena a los cambios que se producían en la derecha europea después de la Revolución Rusa. Ya los sucesos derivados del discurrir de la Primera Guerra Mundial indican cambios en la cultura política de las derechas europeas y, por extensión, españolas. En etapa final de los cambios producidos desde inicios del siglo XX salió a escena el choque donde el bolchevismo, el liberalismo y el fascismo entraron en competición violenta por ver quien dominaba el tablero mundial. La Revolución de 1917, por lo tanto, supuso la ruptura del statu quo ideológico-cultural europeo: por primera vez, triunfaba en el mundo una cultura política diferente del liberalismo ${ }^{33}$.

\footnotetext{
32 Eduardo González Calleja, "La crisis política. La revolución que no tuvo lugar", coord. por Eduardo González Calleja, Anatomía de una crisis. 1917 y los españoles, (Madrid: Alianza Editorial, 2017), 137193. Dentro de la misma obra véase el capítulo de Álvaro Ribagorda, "Los intelectuales en la crisis. El debate público en torno a la guerra europea y la situación española", coord. por Eduardo González Calleja, Anatomía de una crisis. 1917 y los españoles, (Madrid: Alianza Editorial, 2017), 27-66 para un análisis de los debates producidos en España sobre la participación en la Primera Guerra Mundial.

${ }^{33}$ El continuo temporal desde la Primera a la Segunda Guerra Mundial es entendido como una sucesión natural de los hechos desde que Ernst Nolte lo analizase de esa manera en sus obras. Enzo Traverso, $A$
} 
Entendemos que la comprensión de estos cambios es lo que dificulta la catalogación de la dictadura franquista como una continuadora del fenómeno caciquil. El principal de los problemas está en mantener los conceptos «cacique»o «caciquismo», aplicados a un sistema liberal con un mayor o menor grado de participación popular. $\mathrm{O}$ dicho de otra manera: mantenerlos para definir un modelo de gobernanza política dictatorial en la que no existía el juego electoral más o menos libre.

Si la cuestión básica que explica la existencia del fenómeno caciquil es la necesidad de las élites de mantener su poder político a cambio controlar las masas populares mediante favores de diversa índole, ¿qué sentido tiene aplicar ese concepto a un régimen que no necesitaba del mecanismo del juego político? Aquellos autores que se han mostrado próximos a la utilización del concepto «caciquismo» argumentan su posición desarrollando una teoría sobre el posible rechazo de aquéllos que no se inclinaron por él. Es una teoría excelentemente elaborada, pues se sustenta en la evidencia documental de las continuidades de los políticos de las élites municipales.

Para estos autores, la oposición a aquellos términos reside en el supuesto desconocimiento del significado del concepto «caciquismo». Según esos estudios centrados en la cuestión de la teoría política y del análisis de los cuadros políticos-, los que se oponen a aplicar los conceptos no se adentran en el estudio central de la cuestión: «el contraste entre los dichos y los hechos»; o analizar el poder, simplemente. Por lo tanto, aquellos políticos que coparon los puestos de poder durante los primeros compases de la dictadura franquista - y que podían proceder de corporaciones de la Segunda República durante el bienio radical, por ejemplo_-, eran continuadores de las redes clientelares provenientes de la Restauración y que se habían adaptado a los usos políticos de la República ${ }^{34}$. Otros autores matizan esta posición considerando que fue la derecha republicana la que dominó durante el período de la dictadura franquista abundando en el aspecto de la coalición reaccionaria ${ }^{35}$.

sangre y fuego. De la guerra civil europea (1914-1945), (Valencia: Publicacions de la Universitat de València, 2007) lo analiza también de esa manera. La historia de Europa en ese lapso fue un discurrir de tensiones y conflictos entre tres culturas políticas. Las dos guerras fueron hijos de los mismos problemas y crearon un contexto internacional dominado por las tensiones territoriales y las disputas ideológicas entre los diferentes modelos políticos que convivieron en el continente. Un recorrido especial para entender, desde dentro, los cambios de esa etapa de la historia europea es el que ofrece Stefan Zweig en su autobiografía El mundo de ayer.

${ }^{34}$ Óscar Rodríguez Barreira, Miserias del poder..., op. cit., pág. 294.

35 Así lo expresó Emilio Grandío Seoane, "La construcción del franquismo en el entorno urbano: praxis versus política de masas”, coord. por Julio Prada Rodríguez, No solo represión: la construcción del 
La otra perspectiva de interpretación es la existencia de diferentes tendencias dentro de FET de las JONS que tenían objetivos diferentes entre ellas. Según el «pluralismo limitado» - o como se dijo anteriormente, coexistencia de «familias políticas»-, no importaba la significación política previa —aunque existiesen diferencias - , pues todos estaban dentro de un mismo proyecto. Lo que importaba a los gestores, concejales y alcaldes fue ese proyecto. Algunos autores apostaron por reducir la importancia de los antecedentes políticos de los seleccionados para los cargos municipales y primaron la idea de «comunidad de objetivos de las distintas familias del régimen» ${ }^{36}$.

\section{CONCLUSIONES}

Creemos que lectura de los resultados sobre las élites políticas de la dictadura en las siete ciudades gallegas no puede ser entendida como la recuperación del fenómeno caciquil o la división entre familias ideológicas. A la luz de los resultados, y teniendo en cuenta el mantenimiento del régimen dictatorial en el tiempo, entendemos que la explicación sobre la construcción debe buscarse en el fenómeno de la fascistización. Tanto la izquierda como la derecha tuvieron puesta su mirada sobre el fenómeno fascista. Los primeros para luchar contra él. Los segundos para recoger algo de su discurso o procurar que tomase parte de su espacio entre la sociedad. El principal condicionante residía en la derecha que, como se plantea en esta investigación, no era la misma, ni interna ni externamente que la anterior; y todas esas derechas pudieron ser objeto de fascistización. La fascistización sería la capacidad del fascismo de influir en fuerzas políticas y regímenes que, no siendo plenamente fascistas, podían inclinarse hacia su influencia.

La propia composición del que sería el partido único, FET de las JONS, ayudó a que la fascistización se extendiese por todo el espectro de la derecha. El partido único careció en sus inicios del apoyo de la gran burguesía - que participaba de otras opciones como la CEDA o Renovación Española. El partido único también nació de la

franquismo en Galicia, (Madrid: Biblioteca Nueva, 2014) que afirma que la «esencia del franquismo están en esos años»; es decir, los de la Segunda República.

${ }^{36}$ Tal es la perspectiva que dibujó en su momento Ángela Cenarro Lagunas, Cruzados y camisas azules..., op. cit., pág. 78 . 
separación de dos modelos que se desarrollaron de manera paralela: el de Renovación Española de Calvo Sotelo y el de José Antonio Primo de Rivera. El último no quiso participar del proyecto del primero, restándole los apoyos de aquella burguesía. Los denominados por Ismael Saz como «aliados naturales» no llegaron a confluir nunca ${ }^{37}$.

Tal y como se refería al inicio, el partido único se llenó de aquellos provenientes de culturas políticas diferentes a las del fascismo. Los resultados obtenidos en esta investigación nos inclinan hacia esa interpretación. El partido único se habría convertido en un partido de «aluvión», donde había muy pocas camisas viejas. Por eso, los cargos municipales se rellenaban con miembros de la élite de otras épocas políticas o sin experiencia en el ámbito municipal. Falange era, en palabras de algún historiador, un partido artificial ${ }^{38}$. En algunas zonas de España - como Baleares, por ejemplo-, se nota que el partido único fue perdiendo peso con el paso del tiempo; también por la marcha de los militantes más implicados en sus inicios ${ }^{39}$.

Con los resultados obtenidos en esta investigación, y teniendo en cuenta la larga duración, entendemos que resulta difícil mantener una interpretación de la aplicación del modelo caciquil para la selección de las élites locales para explicar el proceso de construcción institucional local de la dictadura franquista. En las ciudades estudiadas se observa un considerable grado de renovación de las élites políticas utilizadas para ocupar los cargos municipales. Resulta evidente que en los primeros compases de la construcción de la dictadura en el nivel local se echó mano de aquellos con experiencia en períodos políticos determinados, especialmente de la dictadura de Primo de Rivera. Pero los porcentajes de hombres sin antecedentes políticos superan a aquéllos que sí tenían una trayectoria previa ${ }^{40}$.

\footnotetext{
${ }^{37}$ El concepto de «aliados naturales» y la explicación de todo el proceso de fracaso del intento de partido fascista en FE, en Ismael Saz, Fascismo y franquismo..., op. cit., pp. 62-63 o en Ismael Saz, Las caras del franquismo, (Granada: Comares, 2013) se refiere a posición subordinada del partido al Estado; lo que es una muestra más de su debilidad, de modo que durante le guerra civil y los primeros años de la dictadura, «no se estaba construyendo un régimen fascista, pero el partido fascista se consolidó como un pilar imprescindible del mismo».

${ }^{38}$ Damián Alberto González Madrid, La Falange manchega (1939-1945)..., op. cit.

39 Joan Mas Quetglas, Els mallorquins de Franco. La Falange i el Moviment Nacional, (Palma: Documenta Balear, 2003) dice que «Los primeros en darse de baja fueron los que, justamente, se habían incorporado para prosperar laboralmente, ganar prestigio social u obtener seguridad jurídica».

${ }^{40}$ El estudio que explica este extremo en otro lugar geográfico es el de Miguel Ángel Arco Blanco, “'Hombres nuevos'. El personal político del primer franquismo en el mundo rural del sureste español (1936-1951)", Ayer, 65, (2007): 237-267.
} 
Con todo, es necesario tener en cuenta un elemento clave de este estudio: se refiere al ámbito municipal urbano. Las ciudades, como núcleos sociales, cuentan con unas dinámicas específicas respecto de otros sistemas de población como pueden ser las villas o aldeas. Existen estudios para el ámbito rural gallego que se apartan sensiblemente de las tendencias de esta investigación ${ }^{41}$. Las urbes son aglomeraciones dinámicas fruto de la mayor aglomeración de población en el espacio. En el territorio rural, o no urbanizado, las posibilidades de encontrar miembros de la élite que pudiesen ocupar cargos municipales se reducen notablemente frente a la gran oferta que existe en las ciudades.

Creemos concluir que la dictadura franquista configuró su élite política en las ciudades gallegas con aquellos hombres que no tenían una trayectoria política previa al golpe de Estado de julio de 1936. El estudio de las series de alcaldes, gestores y concejales de estas urbes permite conocer de una manera mucho más certera los grados de reciclaje y renovación de los hombres que ocuparon los cargos municipales.

Entendemos que se hace necesario, por lo tanto, antes de abordar cuestiones como la naturaleza política de la dictadura, resolver la pregunta sobre la continuidad y discontinuidad de los miembros de la élite política de cada localidad; y también la de cuál fue la orientación económica — por el estudio de los presupuestos-, y cultural de los consistorios.

Seleccionando a aquellos considerados mejores las autoridades dictatoriales pretendieron llegar a lo que José María Salaverría profetizó en 1939: «Ahora con esta nación se puede hacer lo que se quiera. [...] Tenemos buenos escultores, por fortuna, para moldear y acabar el torso y la cabeza de una nueva España» ${ }^{42}$.

\footnotetext{
${ }^{41}$ Respecto a esta matización, véase el trabajo de Julio Prada Rodríguez, "«...en este municipio no se conocía otra política que la de los bandos». Unha aproximación ao poder local na provincia de Ourense (1917-1936)", ed. por Xosé Luis Axeitos, Emilio Grandío Seoane y Ramón Villares, A patria enteira. Homenaxe a Ramón Barreiro Fernández, (Santiago de Compostela: Consello da Cultura Galega, Real Academia Galega, Universidade de Santiago de Compostela, 2008), 277-305. La comparación de este texto citado con este estudio se debe matizar, también, pues abarca desde 1917 a los primeros meses de 1936, una vez se produce el golpe de Estado.

42 José María Salaverría, "La evidencia imperialista", $A B C, 5$ de abril de 1939.
} 


\section{BIBLIOGRAFÍA}

Arco Blanco, Miguel Ángel del. “'Hombres nuevos'. El personal político del primer franquismo en el mundo rural del sureste español (1936-1951)", Ayer, no65 (2007): 237-267.

Aróstegui, Julio. "La historiografía sobre la España de Franco: Promesas y debilidades". Historia contemporánea, $\mathrm{n}^{\circ} 7,(1992): 77-100$.

Barranquero Texeira, Encarnación. Málaga entre la guerra y la posguerra. Málaga: Arguval, 1994.

Calzado Adaria, Antonio y Torres Fabra, Ricardo Camilo. "La formación de un poder omnímodo: la Falange en la Ribera Baixa (1939-1945)". En El régimen de Franco. Congreso internacional, coordinado por Javier Tusell y otros, 29-40. Madrid: UNED, 1993.

Calvo Vicente, Cándida. Poder y consenso en Guipúzcoa durante el franquismo (19361951). Salamanca: Universidad de Salamanca, 1994.

Canales Serrano, Antonio. Las otras derechas: derechas y poder local en el País Vasco y Cataluña en el siglo XX. Madrid: Marcial Pons, 2006.

Casanova, Julián. "La sombra del franquismo: ignorar la historia y huir del pasado". En El pasado oculto. Fascismo y violencia en Aragón (1936-1939), autoría de Ángela Cenarro Lagunas, Julián Casanova y otros. Huesca: Mira Editores, 1999.

--. "Una dictadura de cuarenta años". En Morir, matar, sobrevivir. La violencia en la dictadura de Franco, coordinado por Julián Casanova, 3-50. Barcelona: Crítica, 2004.

Cazorla Sánchez, Antonio. Desarrollo sin reformistas. Dictadura y campesinado en el nacimiento de una nueva sociedad en Almería (1939-1975). Almería: Instituto de Estudios Almerienses, 1999.

Cenarro Lagunas, Ángela. Cruzados y camisas azules: los orígenes del franquismo en Aragón. Zaragoza: Prensas Universitarias de Zaragoza, 1997.

Cerón Torreblanca, Cristian Matías. "La paz de Franco", la posguerra en Málaga: desde los oscuros años 40 a los grises años 50. Málaga: Universidad de Málaga, 2007.

Cobo Romero, Francisco y Ortega López, Teresa María. Franquismo y posguerra en Andalucía oriental. Represión, castigo a los vencidos y apoyos sociales al régimen franquista (1936-1950). Granada: Universidad de Granada, 2005.

Domper Lasús, Carlos. "El franquismo a través de las urnas. Metodología, fuentes y retos para una aproximación electoral al régimen de franco". Política y sociedad, 55, $\mathrm{n}^{\mathrm{0}} 1$ (2018): 115-134.

Eiroa San Francisco, Matilde. Viva Franco: hambre, racionamiento, falangismo: Málaga, 1939-1942. Málaga: Artes gráficas Aprisa, 1995.

Frías Rubio, Ana Rosa. Instituciones sorianas en el franquismo. UNED: Soria, 1988.

Gallego, Ferran. El evangelio fascista. La formación de la cultura política del franquismo. Barcelona: Crítica, 2014.

Ginés i Sànchez, Andreu. La instauració del franquisme al País Valencià. Valencia, Publicacions de la Universitat de València, 2010.

Gómez Roda, José Alberto. Política i poder local. Catarroja: un municipi valencià durant el primer franquisme. Catarroja: Afers, 1998.

González Calleja, Eduardo. "La crisis política. La revolución que no tuvo lugar". En Anatomía de una crisis. 1917 y los españoles, coordinado por Eduardo González Calleja, 137-193. Madrid: Alianza editorial, 2017. 
González Madrid, Damián Alberto. La Falange manchega (1939-1945). Politica y sociedad en Ciudad Real durante la etapa «azul» del primer franquismo. Ciudad Real: Diputación de Ciudad Real, 2004.

Grandío Seoane, Emilio. "La construcción del franquismo en el entorno urbano: praxis versus política de masas". En No solo represión: la construcción del franquismo en Galicia, coordinado por Julio Prada Rodríguez, 61-87. Madrid: Biblioteca Nueva, 2014.

Jerez Mir, Miguel. Élites politicas y centros de extracción en España (1938-1957). Madrid: Centro de Investigaciones Sociológicas, 1982.

Lazo Díaz, Alfonso. Retrato del fascismo rural en Sevilla. Sevilla: Universidad de Sevilla, 1998.

Marín i Corbera, Martí. Els ajuntaments franquistes a Catalunya. Lleida: Pagès editors, 2000.

Mas Quetglas, Joan. Els mallorquins de Franco. La Falange i el Moviment Nacional. Palma: Documenta Balear, 2003.

Millares Cantero, Agustín. "Los monárquicos saludan a la romana. Notas sobre el primer franquismo grancanario". En El Franquismo en Canarias, coordinado por Aarón León Álvarez, 108-145. Santa Cruz de Tenerife: Lecanarien ediciones, 2014.

Molinero, Carme. "Present i futur de la historiografia sobre el règim franquista". En Història i Memòria: el franquisme i els seus efectes als Països Catalans, dirigido por Jordi Font Agulló, 285-301. Valencia: Publicacions de la Universitat de València, 2007.

Moreno Fonseret, Roque. "Los poderes locales en la España del siglo XX: continuidades y cambios en sus élites políticas y en las prácticas clientelares". En Los límites del Estado: la cara oculta del poder local, coordinado por Cristian Matías Cerón Torreblanca, 137-165. Málaga: Universidad de Málaga, 2018.

Nicolás Marín, María Encarna. Instituciones murcianas en el franquismo (1939-1962). Contribución al conocimiento de la ideología dominante. Murcia: Editora Regional de Murcia, 1982.

Parejo Fernández, José Antonio: "Cuando fueron jóvenes... y fascistas". En Políticas del odio. Violencia y crisis en las democracias de entreguerras, dirigido por Fernando del Rey y Manuel Álvarez Tardío, 167-231. Madrid: Tecnos, 2017.

Prada Rodríguez, Julio. A dereita politica ourensá: monárquicos, católicos e fascistas (1934-1937). Vigo: Servizo de Publicacións Universidade de Vigo, 2005.

Prada Rodríguez, Julio. ““....en este municipio no se conocía otra política que la de los bandos'. Unha aproximación ao poder local na provincia de Ourense (19171936)". En A patria enteira. Homenaxe a Xosé Ramón Barreiro Fernández, editado por Xosé Luis Axeitos, Emilio Grandío Seoane y Ramón Villares, 277305. Santiago de Compostela: Consello da Cultura Galega, Real Academia Galega, Universidade de Santiago de Compostela, 2008.

Presas Sobrado, Adrián. "Elites políticas e poder local na Galicia urbana (1939-1951)". Tesis doctoral, Universidade de Vigo, 2019. http://hdl.handle.net/11093/1302.

Requena Gallego, Manuel. "Inmovilismo estructural y adaptación política del régimen franquista". En Castilla-La Mancha en el Franquismo, coordinado por Manuel Requena Gallego, 49-86. Ciudad Real: Biblioteca Añil, 2003.

Ribagorda. Álvaro. "Los intelectuales en la crisis. El debate público en torno a la guerra europea y la situación española". En Anatomía de una crisis. 1917 y los 
españoles, coordinado por Eduardo González Calleja, 27-66. Madrid: Alianza editorial, 2017.

Riquer, Borja de. "El «Nuevo Estado» i l'Ajuntament de Barcelona. La classe política del primer franquisme". L'Avenç, nº126 (1989): 16.22.

Rivero Noval, María Cristina. Política y sociedad en La Rioja durante el primer franquismo (1936-1945). Logroño: Instituto de Estudios Riojanos, 2001.

Rodríguez Barreira, Óscar. Miserias del poder: los poderes locales y el nuevo estado franquista. Valencia: Publicacions de la Universitat de València, 2013.

Sanz Hoya, Julián. La construcción de la dictadura franquista en Cantabria. Instituciones, personal político y apoyos sociales (1937-1951). Santander: Ediciones de la Universidad de Cantabria, 2009.

Saz, Ismael. Fascismo y franquismo. Valencia: Publicacions de la Universitat de València, 2004.

--. Las caras del franquismo. Granada: Comares, 2013.

Souto Blanco, María Jesús. Los apoyos al régimen franquista en la provincia de Lugo (1936-1940). Sada: Ediciós do Castro, 1999.

Traverso, Enzo. A sangre y fuego. De la guerra civil europea (1914-1945). Valencia: Publicacions de la Universitat de València, 2007.

Tusell, Javier. "La dictadura de Franco a los cien años de su muerte". Ayer, no10, (1993): 13-28.

Viver i Pi-Sunyer, Carles. El personal político de Franco (1936-1975). Barcelona: Vicens-Vives, 1978. 